\title{
Cardiac MRI in evaluation of post-operative congenital heart disease and complications
}

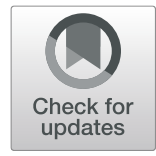

\author{
Samira Saraya ${ }^{*}$, Pamela Woodard ${ }^{2}$, Sanjeev Bhalla ${ }^{2}$, Fernando Gutierrez ${ }^{2}$, Mahmoud Saraya ${ }^{3}$ and \\ Hazem Hamed Soliman ${ }^{1}$
}

\begin{abstract}
Background: The aim of this work is to assess the uses of cardiac MR in evaluating post-operative congenital heart disease procedures and related complications.

Results: This is a retrospective study done in between December 2015 and October 2017, including 71 patients with age ranging from 6 months to 33 years (mean age 16.75). All of the patients were referred for post-operative evaluation after echocardiographic examination to exclude post-operative complications and to plan for reintervention if needed. Forty-three percent of patients suffered from post-operative complications. The most common congenital heart disease coming for post-operative evaluation was tetralogy of Fallot (TOF) which represented $32 \%$ of the cases. The most common post-operative complication in all procedures was pulmonary branch stenosis (12.6\%) followed by patch dilatation (9.8\%) and right ventricular failure (7\%). In 7 patients following TOF repair, there was aneurysmal dilatation of the patch with significant pulmonary regurgitation. The regurgitation fraction was less than $40 \%$ in 3 of them, while the remaining 4 cases showed regurgitation fraction of more than $40 \%$, an indication for re-intervention.
\end{abstract}

Conclusion: MRI is an extremely useful imaging method for evaluation of normal and abnormal findings after surgical repair for congenital heart disease. It is effective in providing long-term surveillance and identifying postprocedural complications, which allowed us to further intervene on a timely manner when deemed necessary.

Keywords: Cardiac, MRI, Post-operative, Congenital, Heart

\section{Background}

Congenital heart disease (CHD) patient survival has greatly improved in recent decades, largely in part to technical advances related to diagnosis and treatment. Many of these patients have had palliative and corrective surgical procedures, creating a need for long-term surveillance so that anatomic parameters can be monitored and complications can be identified on a timely basis. Cardiac magnetic resonance (CMR) imaging is a non-invasive modality that has proven to be effective in determining both cardiac function and anatomy. It has become an integral and crucial part of ongoing follow-up of these patients because it

\footnotetext{
* Correspondence: semsaraya@yahoo.com

${ }^{1}$ Diagnostic and Intervention Radiology Department, Faculty of Medicine,

Cairo University, Kasr Al-Ainy, Cairo, Egypt

Full list of author information is available at the end of the article
}

is uniquely suited for early detection of post-operative complications and to help plan re-intervention whether surgical or catheterization-based. Appropriate cardiac MR imaging protocols tailored to the post-operative anatomy and the specific clinical problems that may be encountered during follow-up [1].

In this paper, we performed a retrospective analysis to evaluate the uses of cardiac MR in evaluating the postoperative congenital heart disease patient and demonstrate how cardiac MR contributed to the multidisciplinary evaluation of these patients.

\section{Methods}

\section{Study population}

Cardiac MR examinations performed from December 2015 to October 2017 in patients with congenital heart 
disease post-surgical repair referred for a clinically necessary standard of care cardiac MR examination from the cardiothoracic surgery and cardiology departments at our institute were collected for analysis. This study was approved by the ethics committee and the institutional review board at our institution.

\section{Magnetic resonance imager}

Both adults and children with congenital heart disease were scanned on a Philips Gyroscan Intera (1.5 T) whole-body MRI scanner housed in our radiology department.

\section{Patient position}

All patients were examined in supine position, head first. The patients were offered headphones to reduce the repetitive gradient noise and at the same time allow the patient to hear the breath hold instructions. ECG leads and PEAR (phase encoding artifact reduction) sensors were applied. A small surface coil (C1 coil, Philips) was utilized for infants and toddlers, while the phased array body coil (Synergy, Philips) was utilized for older children and adults.

\section{Sedation}

Infants and small children up to the age of 4 years were sedated by oral chloral hydrate $(75 \mathrm{mg} / \mathrm{kg}$ body weight), while older children and adults underwent the examination without sedation.

\section{Imaging parameters}

The imaging protocol varied according to the age of the patient, relevant anatomy, and the expected postoperative complications. Sequences routinely performed included the following:

\section{A- Black-blood spin echo (BBSE)}

BBSE was used to delineate both cardiac and extracardiac anatomy due to its high tissue-to-blood characteristics. An additional advantage of BBSE was its low sensitivity to metallic susceptibility artifacts allowing better assessment of cardiac anatomy in the presence of intracardiac or intra-vascular metallic devices.

\section{B- Bright-blood gradient echo cine imaging}

This was obtained by utilizing balanced steady state free precession (B-SSFP). In this sequence, the blood appears white. This cine technique was used in the evaluation of the ventricular volumes, masses, and ejection fraction as well as permitting the identification of valvular regurgitation, stenosis, or turbulent flows across septal defects.

\section{C- Phase-encoded flow imaging}

This technique was used for quantification of flow volumes, regurgitation fraction, peak flow velocities and shunt volumes via measuring the ratio between pulmonary flow volume $(\mathrm{Qp})$ and aortic flow volume $(\mathrm{Qs})$, thus allowing the delineation of the severity of stenotic or regurgitant valves, peripheral pulmonary branch stenosis, and shunt fraction.

The imaging planes that were used in this study were the three standard orthogonal axes of the thorax: transverse, coronal, and sagittal images (black blood); short and long axis images of the heart (SSFP cine); and phase encoding flow quantification across the aortic and pulmonary valves.

In cases where late gadolinium enhancing (LGE) images were required, gadolinium chelate contrast material $(0.1-0.2 \mathrm{mmol})$ gadopentetate dimeglumine was intravenously administered followed by a cardiac-gated segmented inversion recovery-prepared (200-300 ms) fast gradient-echo sequence $10-15$ min later.

\section{Image interpretation}

Cardiac MRI examinations were performed under the supervision of an expert radiologist (6 years experience) for exam acquisition, interpretation, and post-processing; then, the images were reviewed by 2 readers ( 6 and 10 years experience in cardiac MRI) for the following: complications such as pulmonary patch aneurysmal dilatation and pulmonary regurgitation fraction (RF). Grading of regurgitation was classified as mild if less than $20 \%$, moderate if 20 to $40 \%$, and severe if more than $40 \%$, pulmonary artery branch stenosis, tricuspid valve regurgitation, and right ventricular ejection fraction (RVEF); classified as > 70\% "hyperdynamic", 55-70\% "normal", 45-54\% "lownormal/borderline low" 40-45\% " mildly reduced", 30$44 \%$ "moderately reduced", <30\% "severely reduced", where RV failure is considered if RVEF is $<40 \%$, right ventricular end diastolic volume (RVEDV) index; classified as 100-110 "borderline", 110-130 "mild", 130-170 "moderate", > 170 "severe".

Additionally, valvular morphology and anatomical details such as situs, AV concordance, VA concordance, great vessel relationship, septation defects, size, and pericardial effusion were evaluated. Extracardiac findings including those affecting the aorta, pulmonary arteries, pulmonary venous drainage, systemic venous drainage, coronary arteries, lungs, and pleura, as well as upper abdominal abnormalities, were also noted and described when present.

\section{Statistical analysis}

IBM SPSS statistics [V.21.0, IBM Corp., USA, 2012] were used for data analysis. 


\section{Results}

We identified 71 cardiac MRI examinations performed during this time period in patients with congenital heart disease. Patient age ranged from 6 months to 33 years (mean age 16.75), 37 males, 34 females, with 43 patients less than 18 years of age.

All of the patients were referred for post-operative evaluation after echocardiographic examination to exclude post-operative complications and to plan for reintervention if needed.

The 71 patients included 23 patients post tetralogy of Fallot (TOF) repair, and 14 patients post d-transposition of the great vessels (TGA) repair, with surgical type and other patient conditions as identified in Graph 1. The type of procedure done for every patient is demonstrated in Graph 2.

Different complications were detected in each procedure (Table 1) as follows: In patients post TOF repair (presented in Graph 3), 7 patients had aneurysmal dilatation of the patch with significant pulmonary regurgitation. The regurgitation fraction was less than $40 \%$ in 3 of them, while the remaining 4 cases show regurgitation fraction of more than $40 \%$, an indication for reintervention. Nine cases of the 23 showed pulmonary branch stenosis ( 7 of them affects the left main branch, while 2 patients affect the right main branch). Right ventricular failure was detected in 4 patients (EF less than $40 \%$ ) with one of them showing delayed trans-mural enhancement denoting scarring. Three patients showed marked right ventricular dilatation with severe tricuspid regurgitation.

In patients post TGA repair, the following complications were detected (Graph 4). The patient who had Senning procedure (Fig. 1) showed RV failure, while the other patient who had Rastelli (Fig. 2) procedure showed aneurysmal dilatation of the baffle causing extensive bony erosions of the sternum. One of the patients who did pulmonary banding showed band loosening, while another one showed pulmonary artery stenosis (Fig. 3).
In DORV patients who did Rastelli procedure and MBT shunt, no complications were detected but one of the three patients who did pulmonary artery banding showed stenosis.

No complications were detected in patients who underwent Glenn procedure (Fig. 4a, b). However, a case of pulmonary banding for D-TGA showed loosening detected by velocity encoded images (Fig. 4c). Fontan (Fig. 5) and Jatene (Fig. 6) procedures for single ventricle/ complex congenital heart disease repair showed no postoperative complications.

In patients treated for pulmonary artery stenosis, 3 patients had obstruction of the MBT shunt.

Restenosis was detected in 2 patients who had balloon angioplasty (Fig. 7) for aortic coarctation, while 1 patient presented with restenosis after end-to-end anastomosis.

Late gadolinium enhancement was performed in cases with clinical suspicion of heart failure $(N=15)$ to assess for myocardial viability. One of these cases revealed signs of transmural late gadolinium myocardial enhancement denoting scarring.

\section{Discussion}

Cardiac specialized radiologists are in dire need to understand the different interventional procedures used in the management of congenital heart disease. A thorough understanding of the normal post-operative findings is required to identify post-operative complications [2].

Echocardiography is still considered as the first modality in the evaluation of post-operative complications following congenital heart disease procedures due to its known advantages of being safe, affordable, and lack of ionizing radiation together with its superior capabilities in the delineation of the intracardiac anatomy and cardiac physiological functions. However, due to operator dependability and limitation of the narrow acoustic window, it confronts difficulties in the visualization of extracardiac anatomy [3].

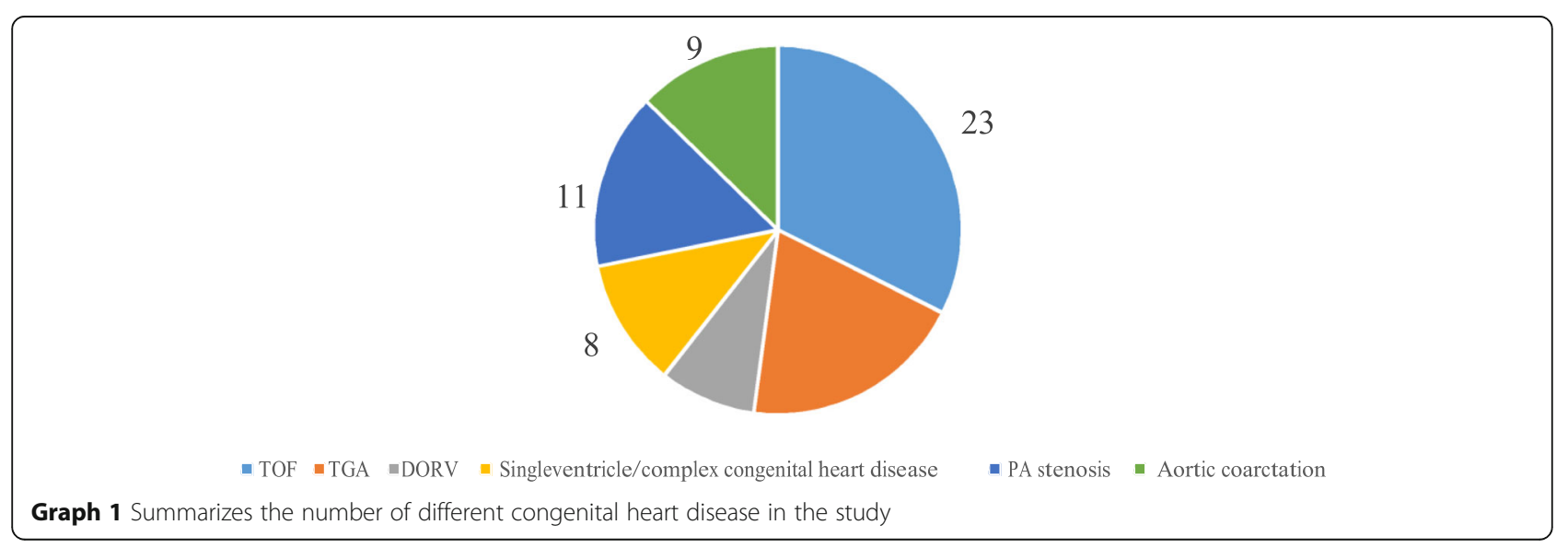




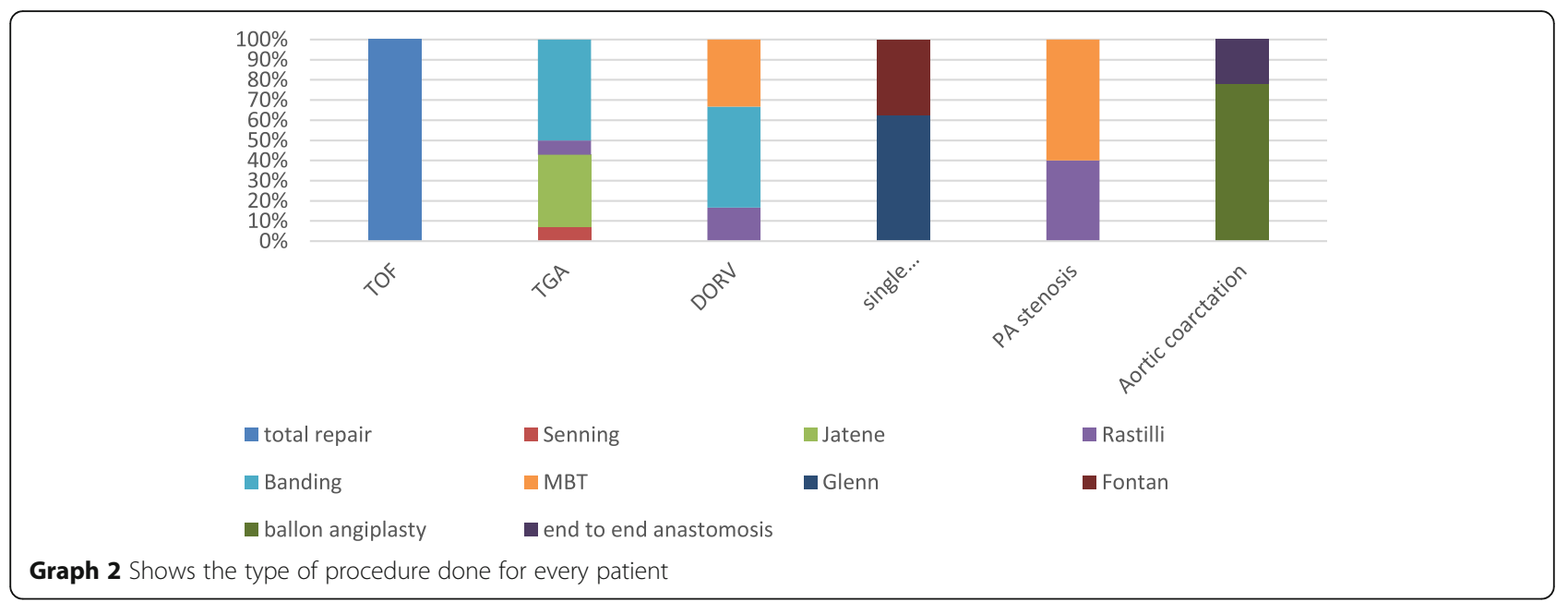

Both cardiac CT and cardiac MRI are considered as minimally invasive techniques in the evaluation of extracardiac post-operative vascular complications. However, on the contrary to cardiac CT, cardiac MRI is superior in its inherent capability to identify intracardiac anatomical, functional, and structural abnormalities or postoperative complications following congenital heart disease surgical procedures [3].

Our study demonstrated that cardiac MRI was helpful in demonstrating post-operative complications. As

Table 1 Table summarizing the different complications detected in the different post-operative procedures performed in various $\mathrm{CHD}$

\begin{tabular}{|c|c|c|c|c|c|c|c|}
\hline & $\begin{array}{l}\text { No. of } \\
\text { patients }\end{array}$ & Procedure & $\begin{array}{l}\text { No. of } \\
\text { patients }\end{array}$ & Complications & $\begin{array}{l}\text { No. of patients with } \\
\text { complications per procedure }\end{array}$ & $\begin{array}{l}\% \text { per } \\
\text { procedure }\end{array}$ & $\begin{array}{l}\% \text { per total no. of } \\
\text { patients }\end{array}$ \\
\hline \multirow[t]{4}{*}{ TOF } & \multirow[t]{4}{*}{23} & \multirow[t]{4}{*}{ Total repair } & \multirow[t]{4}{*}{23} & $\begin{array}{l}\text { Patch dilatation }+ \\
\mathrm{PR}^{*}\end{array}$ & 7 & 30.4 & 9.8 \\
\hline & & & & $\begin{array}{l}\text { Pulmonary branch } \\
\text { stenosis }\end{array}$ & 9 & 39.1 & 12.6 \\
\hline & & & & $R V F^{*}$ & 4 & 17.3 & 5.6 \\
\hline & & & & $R V D^{*}+T R^{*}$ & 3 & 13.04 & 4.22 \\
\hline \multirow[t]{5}{*}{ TGA } & \multirow[t]{5}{*}{14} & Senning & 1 & RVF & 1 & 100 & 1.4 \\
\hline & & Rastelli & 1 & Baffle dilatation & 1 & 100 & 1.4 \\
\hline & & \multirow{2}{*}{$\begin{array}{l}\text { Pulmonary } \\
\text { banding }\end{array}$} & \multirow[t]{2}{*}{7} & Loosening & 1 & 14.2 & 1.4 \\
\hline & & & & $\begin{array}{l}\text { Pulmonary artery } \\
\text { stenosis }\end{array}$ & 1 & 4.2 & 1.4 \\
\hline & & Jatene & 5 & No complications & 0 & 0 & 0 \\
\hline \multirow[t]{3}{*}{ DORV } & \multirow[t]{3}{*}{6} & Rastelli & 1 & No complications & 0 & 0 & 0 \\
\hline & & MBT & 2 & No complications & 0 & 0 & 0 \\
\hline & & $\begin{array}{l}\text { Pulmonary } \\
\text { banding }\end{array}$ & 3 & $\begin{array}{l}\text { Pulmonary artery } \\
\text { stenosis }\end{array}$ & 1 & 33.3 & 1.4 \\
\hline \multirow[t]{2}{*}{ Single ventricle } & \multirow[t]{2}{*}{8} & Glenn & 5 & No complications & 0 & 0 & 0 \\
\hline & & Fontan & 3 & No complications & 0 & 0 & 0 \\
\hline \multirow{2}{*}{$\begin{array}{l}\text { Pulmonary artery } \\
\text { stenosis }\end{array}$} & \multirow[t]{2}{*}{11} & MBT & 9 & Obstruction & 3 & 33.3 & 4.22 \\
\hline & & Rastelli & 2 & No & 0 & 0 & 0 \\
\hline \multirow[t]{2}{*}{$\begin{array}{l}\text { Aortic } \\
\text { coarctation }\end{array}$} & \multirow[t]{2}{*}{9} & $\begin{array}{l}\text { Balloon } \\
\text { angioplasty }\end{array}$ & 7 & Restenosis & 2 & 28.5 & 2.8 \\
\hline & & $\begin{array}{l}\text { End-to-end } \\
\text { anastomosis }\end{array}$ & 2 & Restenosis & 1 & 50 & 1.4 \\
\hline
\end{tabular}




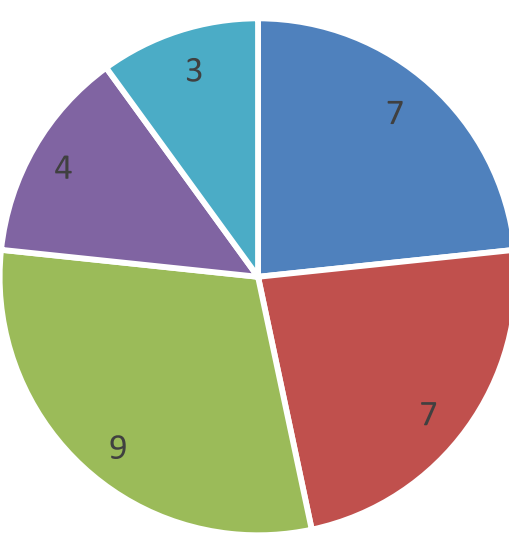

$$
\begin{aligned}
& \text { - pulmonary patch aneurysmal dilatation } \\
& \text { - pulmonary branch stenosis } \\
& \text { - tricuspid regurge }
\end{aligned}
$$

$$
\text { - pulmonary regurge }
$$

- RV failure

Graph 3 Shows different post-operative complications following total repair for TOF

described above, post-operative complications were noted in over $40 \%$ of patients with follow-up cardiac MRI examinations. The commonest encountered congenital heart disease was tetralogy of Fallot (32\%).

The postoperative CMR criteria for evaluation of total repair of tetralogy of Fallot in our study included RV volume, RVEF, and pulmonary regurgitant fraction (RF) which was in agreement with the study by Mercer-Rosa et al. in 2012 [4]. In addition, we evaluated for the presence of patch dilatation and pulmonary artery branch stenosis. Our results showed that the most prevalent complication was pulmonary branch stenosis (39\%) of which 7 affected the left pulmonary and only 2 affected the right pulmonary artery. This was likely due to the anatomical angular origin of the left pulmonary in comparison to the right pulmonary artery which appears as a normal anatomical continuation of the main pulmonary artery. Mercer-Rosa study demonstrated that pulmonary regurgitation $(90 \%)$ was detected post-operatively which is a very high percentage in comparison to only $30 \%$ of the cases displaying pulmonary regurgitation in our study. However, we both showed considerable agreement in the percentage of severe pulmonary regurge ( 44 and $55 \%$, respectively) which mandated surgical interference.

In our study following TOF repair, we also detected tricuspid regurge $(n=3)$ and right ventricular failure (EF

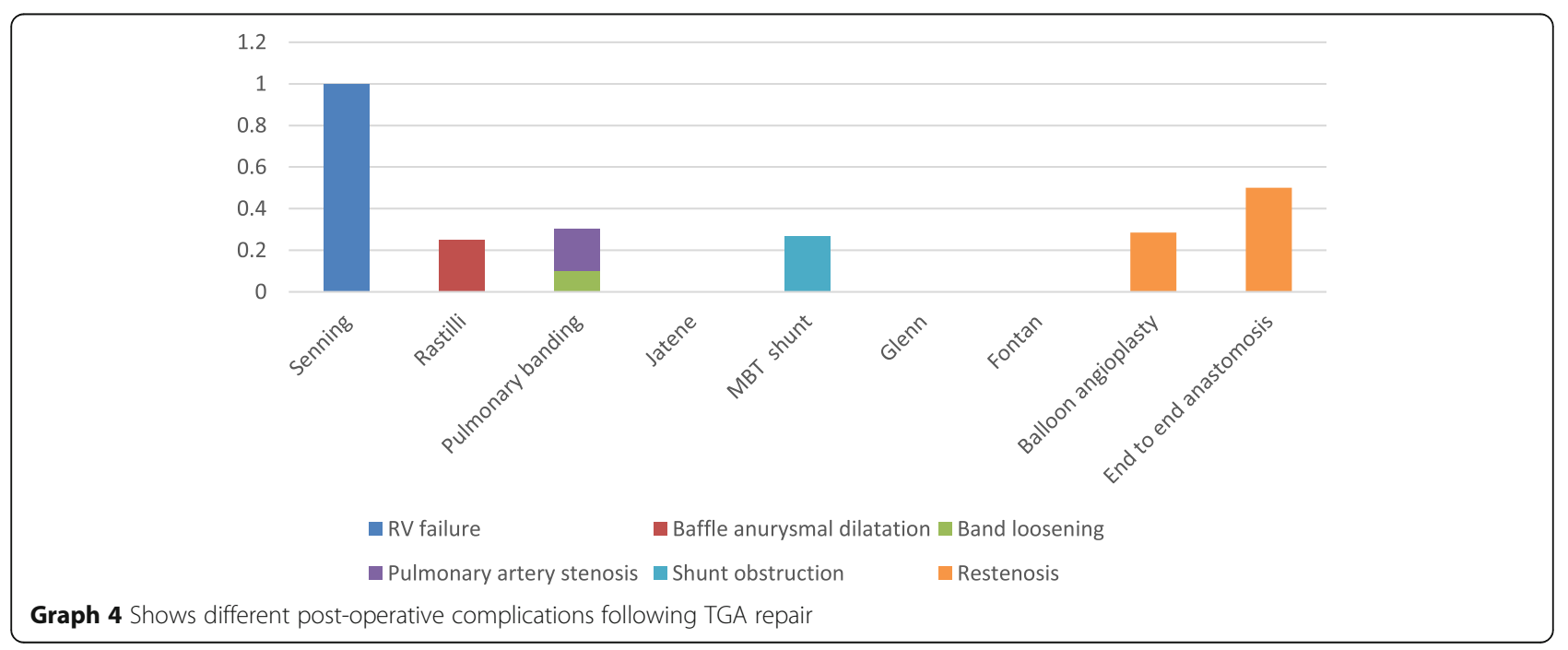




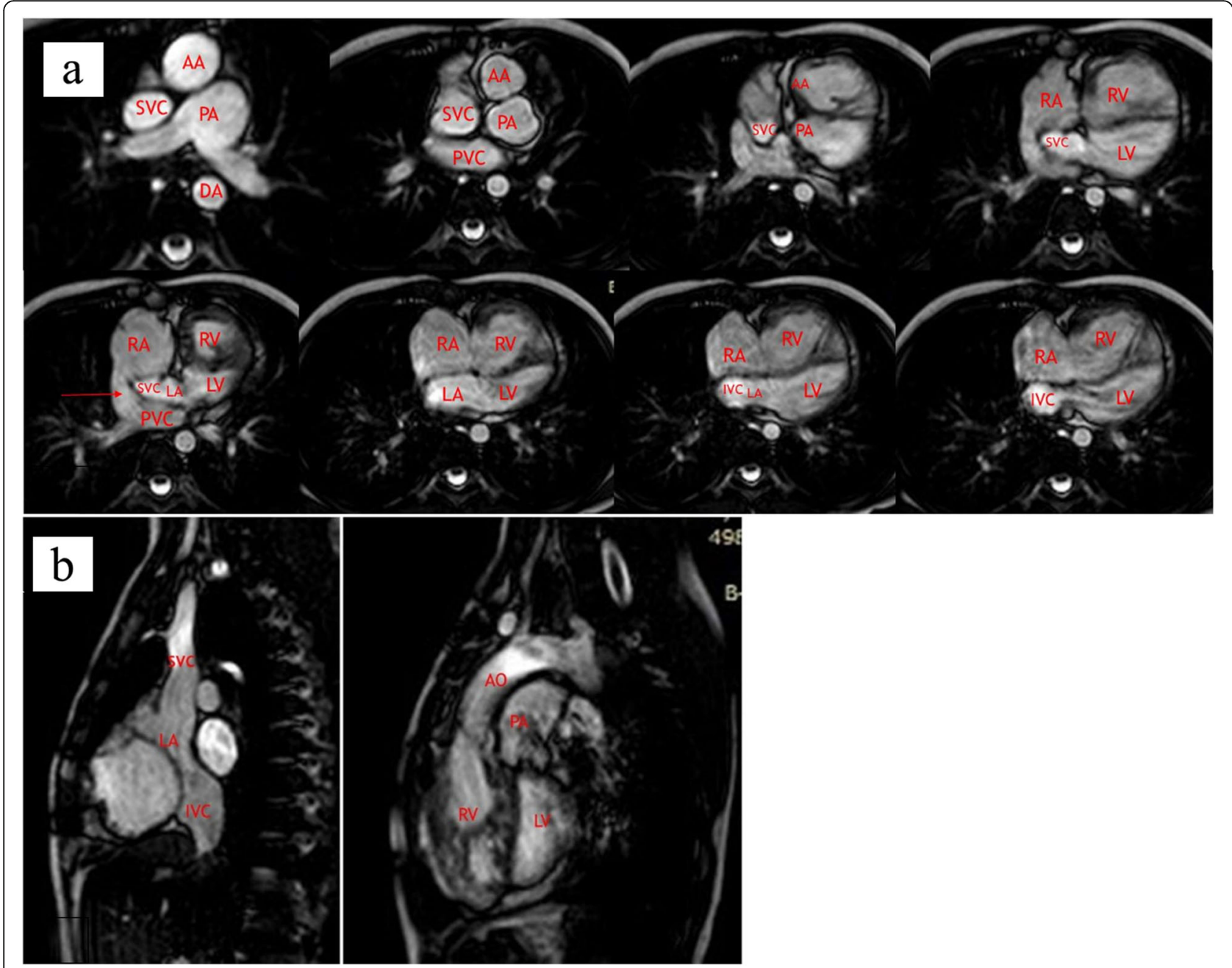

Fig. 1 Sequential axial and sequential sagittal images SSFP, post Senning operation for TGA repair showing the systemic venous blood from the SVC and IVC is redirected to the left ventricle, and pulmonary venous blood from the pulmonary veins is redirected to the right ventricle (arrow). a Sequential axial images. b Sequential sagittal images. AA ascending aorta, DA descending aorta, IVC inferior vena cava, LA left atrium, LV left ventricle, PA pulmonary artery, PVC pulmonary venous confluence, RA right atrium, RV right ventricle, SVC superior vena cava

$<40 \%)$ in 4 cases; one of which displayed late transmural gadolinium enhancement denoting myocardial fibrosis and scarring. Oosterhof et al. in 2005 [5] demonstrated similar results to our study showing that patients with delayed mural enhancement following TOF repair showed low right ventricular ejection fraction $(43 \% \pm$ 6.3) and large end-diastolic volume $\left(175 \mathrm{~mL} / \mathrm{m}^{2} \pm 42\right)$.

The second most common surgically repaired congenital heart disease in our study was TGA. Senning atrial switch (physiological repair) was used in 1 case and Jatene arterial switch procedure (anatomic repair) was performed in 5 cases. The Senning procedure presented by dilated RV, reduced RVEF (33\%), and increased EDV denoting right ventricular failure. Roest et al. in 1999 [6] described similar post-operative findings and attributed this to the continuous exposure of the right ventricle to systemic pressure resulting in compensatory hypertrophy and eventually ventricular failure.

In our study, the 5 Jatene arterial switch procedures revealed no significant complications. However, it is worth mentioning that several studies including Roest et al. [6] reported several post-operative complications including neo-aorta dilatation, pulmonary artery stenosis, and coronary artery ischemic changes due to coronary artery relocation surgery.

Rastelli procedure was performed in a case of TGA and a case of DORV in our study. In this procedure, a valved conduit connects the right ventricle to the pulmonary artery and an intracardiac baffle is passed through the VSD transferring oxygenated blood from the left ventricle to the aorta. We encountered marked baffle dilatation in the TGA case. Kreutzer et al. in 2000 

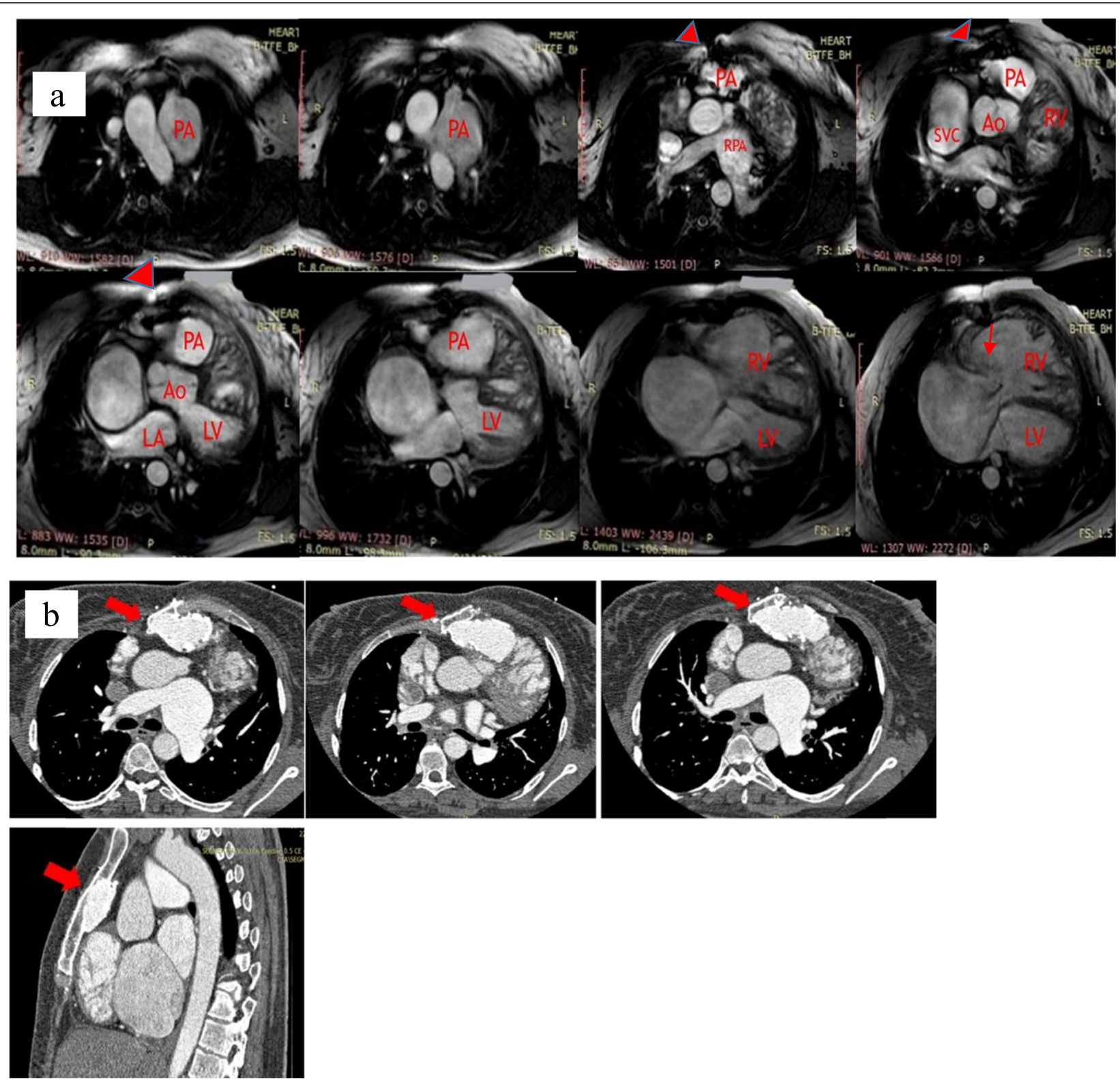

Fig. 2 a Sequential axial SSFP images post Rastilli operation for TGA and pulmonary atresia correction showing dilated pulmonary conduit causing sternal erosions (arrowheads) and tricuspid regurgitation (thin arrow). b Sequential axial and coronal CT demonstrating the sternal erosions (arrows). Ao aorta, LA left atrium, LV left ventricle, PA pulmonary artery, RPA right pulmonary artery, SVC superior vena cava

[7] described baffle dilatation as a complication of Rastelli procedure, but he also added other complications including biventricular failure, conduit obstruction, and pulmonary branch stensosis.

Pulmonary artery banding (PAB) was performed in 10 cases in our study (7 TGA and 3 DORV). PAB is commonly used to prevent irreversible pulmonary hypertension with volume overload and pulmonary vasculature hypertrophy. Two of these cases were complicated by stenosis and one case by loosening of the band. Miura et al. study in 2004 stated that cardiac MRI can be used to identify the positioning of the $\mathrm{PAB}$ as band migration may result in pulmonary branch stenosis. It also described postoperative stenosis secondary to band erosions with possible pseudoaneurysm formation [8].

Modified Blalock-Taussig shunt (MBT) is a prosthetic graft connecting the ipsilateral subclavian and pulmonary arteries to induce and accelerate the growth of the pulmonary arterial tree likely as a preliminary step before total repair of a congenital heart disease [2]. Our study included 11 MBT shunts performed in DORV and pulmonary artery stenosis cases of which 3 were totally obstructed. 

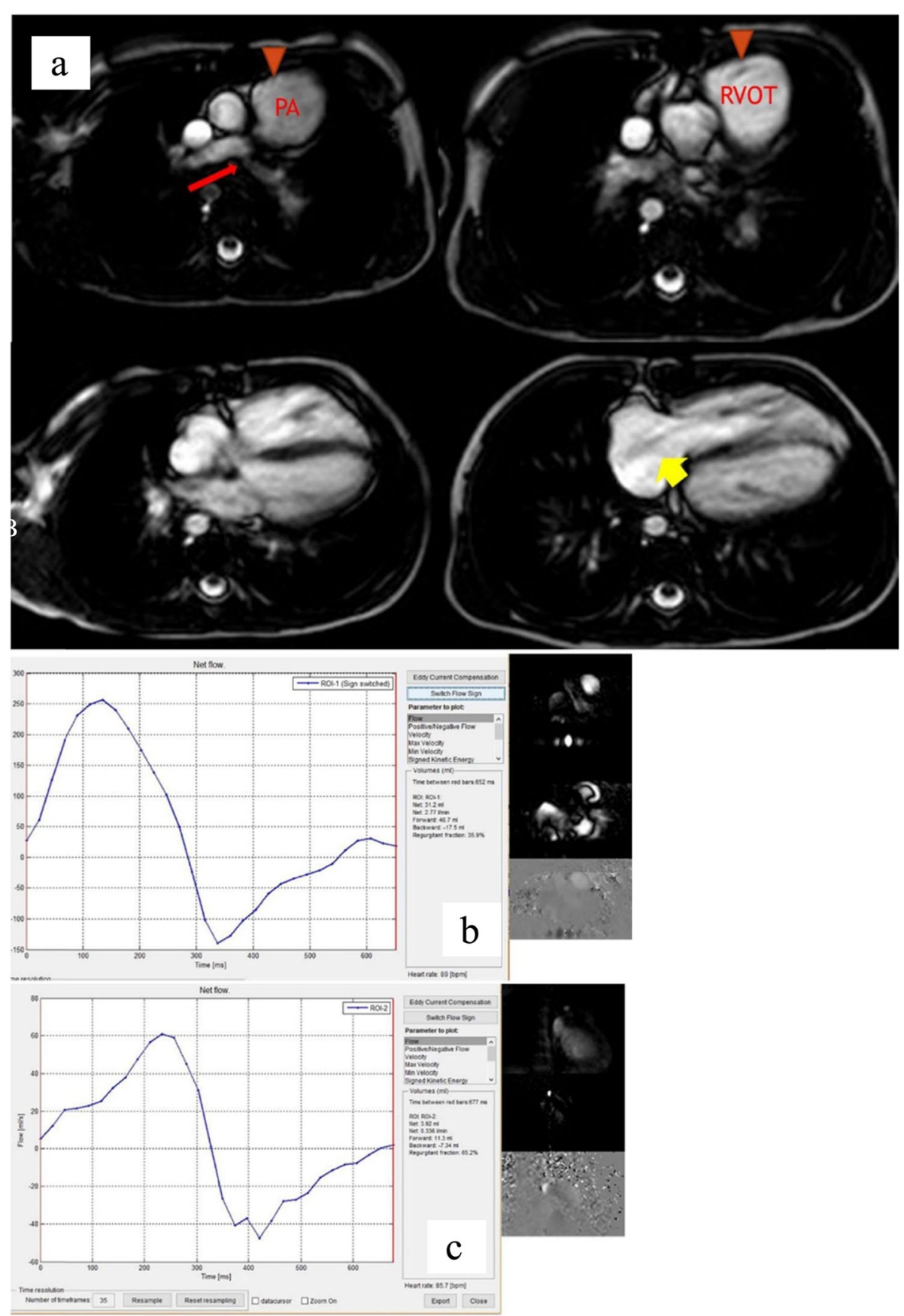

Fig. 3 A case of post TOF repair. a Dilated pulmonary patch and RVOT (arrowhead), left pulmonary artery stenosis (arrow), and tricuspid regurge (short arrow). b MPA RF 36\%. c LPA RF 65\%. LPA left pulmonary artery, MPA main pulmonary artery, PA pulmonary artery, RF regurge fraction, RVOT right ventricular outflow tract

This study also included 8 cases of functional single ventricles. They performed systemic venous-to-pulmonary artery shunts (5 Glenn and 3 Fontan procedures). The aim of the procedures was to transfer deoxygenated venous blood to the pulmonary circulation without increasing the ventricular volume or pressure load. The original Glenn shunt connected the superior vena cava (SVC) to the distal end of the right pulmonary artery. This only allowed perfusion of the right lung. A modified procedure is now performed consisting of end-to-side anastomosis of the SVC and the right pulmonary artery, thus allowing perfusion of both lungs [9]. The Fontan procedure is usually preceded by 

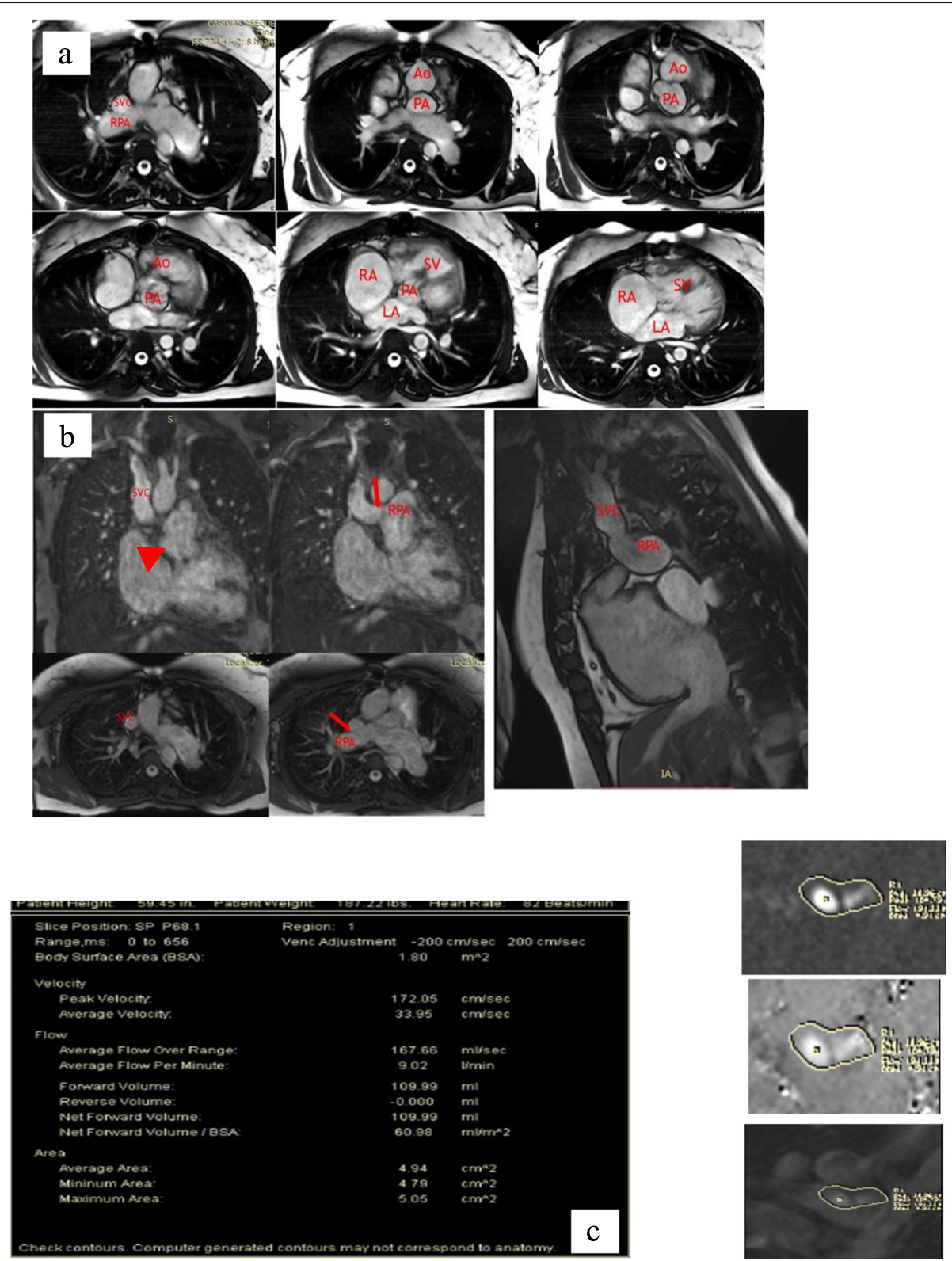

Fig. 4 A case of D-TGA had Glenn shunt and pulmonary banding. a Sequential axial SSFP images showing D-TGA, single ventricle, pulmonary banding (arrowhead), and Glenn shunt (SVC connected to RPA). b Coronal, axial, and sagittal SSFP images demonstrating Glenn shunt. c Pulmonary band loosening diagnosed by velocity encoding images. Ao aorta, LA left atrium, PA pulmonary artery, RA right atrium, RPA right pulmonary artery, SV single ventricle, SVC superior vena cava

a Glenn procedure. It aims to directly transfer systemic venous blood to the pulmonary circulation [10]. No complications were detected in any of the performed procedures.

Post-operative evaluation of Fontan procedure must include pulmonary artery dimensions and the ventricular function via using cine MRI and gadolinium-enhanced 3D MRA. The McGoon ratio which is the sum of the diameters of the central pulmonary arteries just after branching from the main pulmonary artery divided by the diameter of the descending aorta at the level of the diaphragm is to be calculated. If the ratio is less than 1.8, increased risk of Fontan circuit dysfunction and death is expected. MRI is also beneficial in detecting other postoperative complications such as pulmonary arteriovenous malformations, collateral veins or arteries, atrio-ventricular valve regurgitation, atrial enlargementrelated complications, and arrhythmias [11]. 


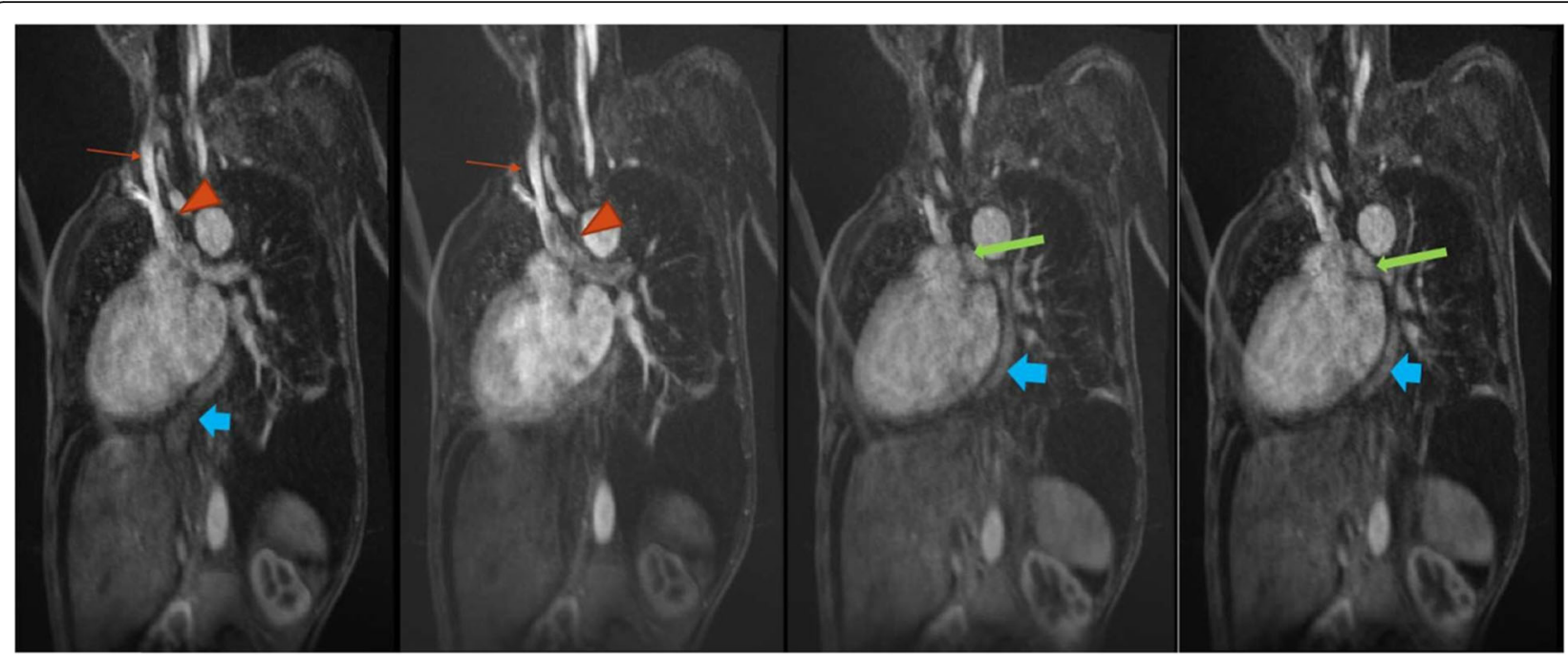

Fig. 5 MRA post Fontan for TGA with patent total cavopulmonary connection. SVC (thin arrow) connected to RPA (arrow head), while IVC (blue arrow) connected to LPA (green arrow). IVC inferior vena cava, LPA left pulmonary artery, MRA MR angiography, RPA right pulmonary artery, SVC superior vena cava

Our study also included 9 cases of post-aortic coarctation repair (7 cases via percutaneous balloon angioplasty and 2 cases via surgical end-to-end anastomosis). The only post-operative complication demonstrated was restenosis or re-coarctation. Other complications may include left ventricular dysfunction, aneurysmal dilatation, or perianastomitc leakage. 3D-MRA can be utilized to delineate the diameter, site, and length of the re-coarctated segment, while phase encoding MR techniques are used for quantification of the hemodynamic gradient across the coarctation site. This plays a crucial role in the decision for re-intervention. If the pressure gradient over the coarctation is $>20$ $\mathrm{mmHg}$, this usually requires re-intervention [12].

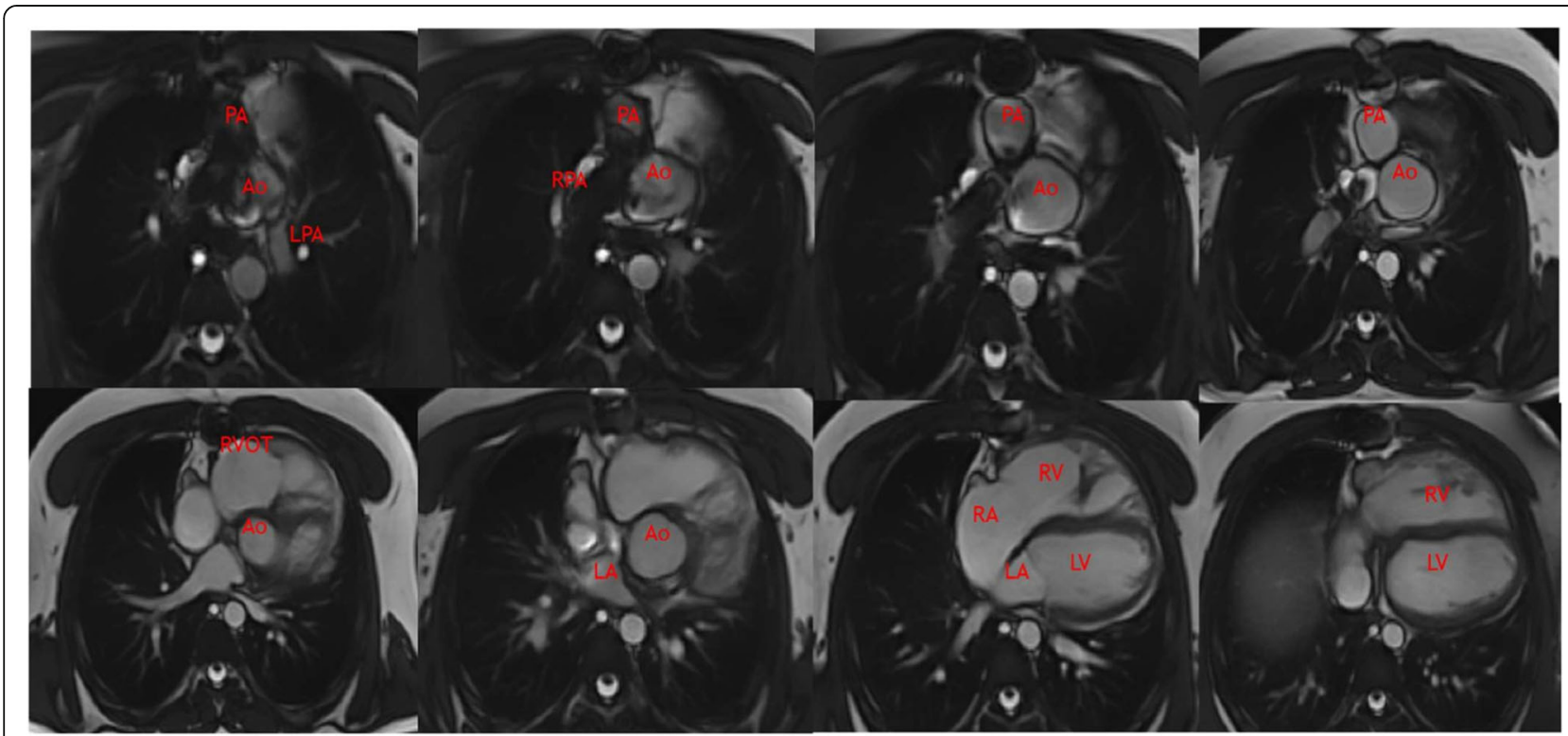

Fig. 6 A case of post Jatene procedure for TGA correction: sequential axial SSFP images showing arterial switch, stent of MPA, RPA, and LPA showing mildly dilated and hypertrophied RV. Ao aorta, LA left atrium, LPA left pulmonary artery, LV left ventricle, PA pulmonary artery, RA right atrium, RPA right pulmonary artery, RV right ventricle, RVOT right ventricular outflow tract 


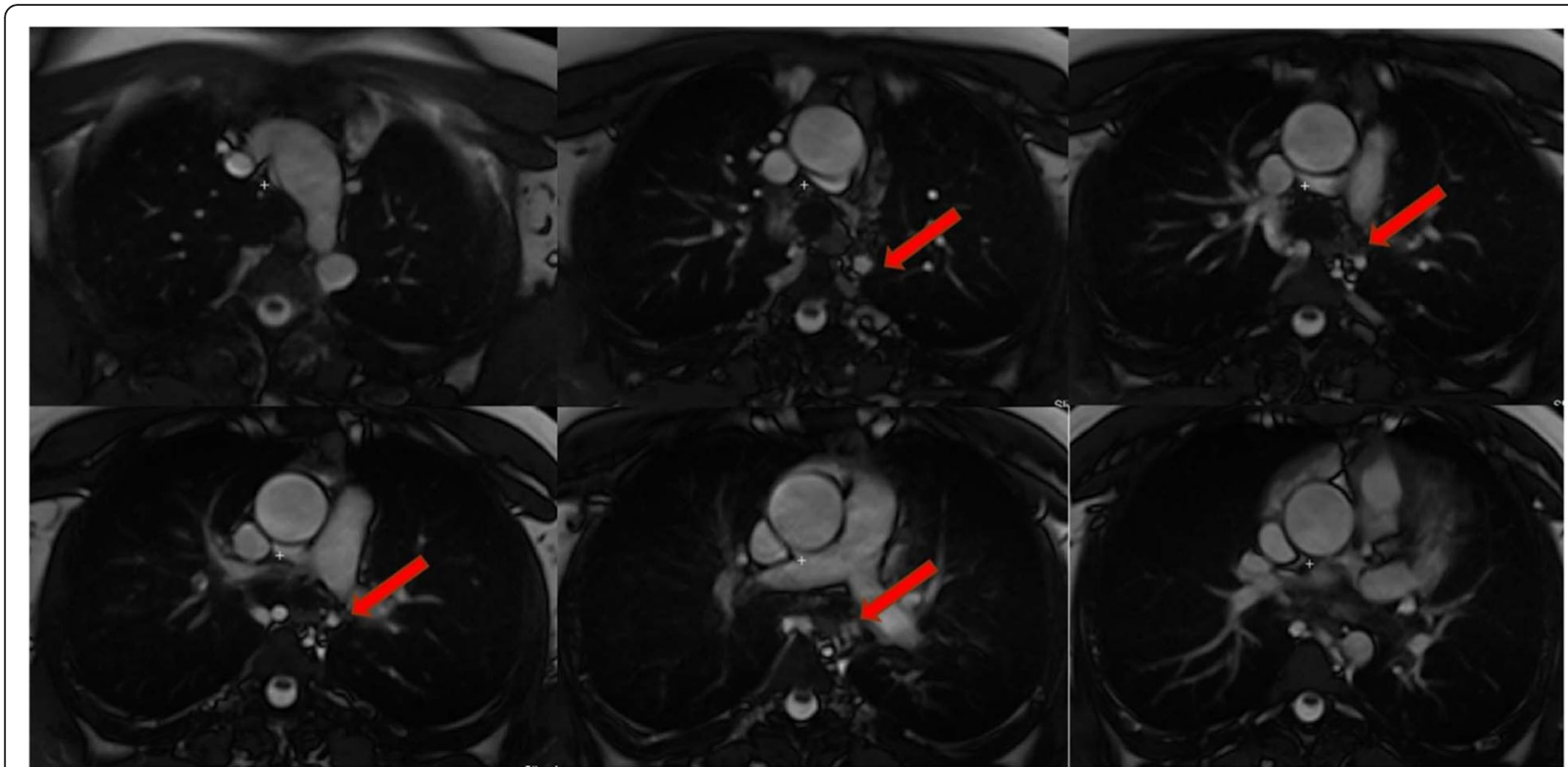

Fig. 7 A case of post-balloon angioplasty for aortic stenosis: sequential axial SSFP images showing restenosis (arrows)

\section{Conclusion}

In conclusion, MRI is an extremely useful imaging method for the evaluation of normal and abnormal findings after surgical repair. As noted, we have been able to effectively identify post-procedural anatomical and functional intra- and extracardiac information, thus allowing accurate diagnosis of postoperative complications in $43 \%$ of patients. This allowed us to further intervene on a timely manner when deemed necessary for the wellbeing of the patient.

\section{Abbreviations}

CHD: Congenital heart disease; MR: Magnetic resonance; PEAR: Phase encoding artifact reduction; SSFP: Steady state free precession; LGE: Late gadolinium enhancing; TOF: Tetralogy of Fallot; TGA: Transposition of the great vessels; SVC: Superior vena cava; D-TGA: Dextroposed transposition of the great arteries; IVC: Inferior vena cava; PDA: Patent ductus arteriosus; RVOT: Right ventricular outflow tract

\section{Acknowledgments}

Not applicable

\section{Authors' contributions}

All authors have read and approved the manuscript. Samira Saraya (SS), Pamela Woodard (PW), Sanjeev Bhalla (SB), Fernando Gutierrez (FG), Mahmoud Saraya (MS) and Hazem Hamed Soliman (HHS) contributed to this work. HHS and SS designed the research. HHS, MS, and SS performed the research. HHS, SS, PW, MS, and SB analyzed the data. HHS, SS, PW, and FG wrote the paper.

\section{Funding}

The study has no funding from any resource.

\section{Availability of data and materials}

The datasets used and/or analyzed during the current study are available from the corresponding author on reasonable request.
Ethics approval and consent to participate

This study was approved by the research ethic committee of the Radiology Department of the Faculty of Medicine at Cairo University on 08/01/2018; reference number of approval: 894-2017. All patients included in this study gave a written informed consent to participate in this research. If the patient was less than 16 years old or unconscious at the time of the study, written informed consent for their participation was given by their parent or legal guardian.

\section{Consent for publication}

All patients included in this study gave a written informed consent to publish the data contained within this study. If the patient was less than 16 years old or unconscious at the time of the study, written informed consent for publication was given by their parent or legal guardian.

\section{Competing interests}

The authors declare that they have no competing interests.

\section{Author details}

'Diagnostic and Intervention Radiology Department, Faculty of Medicine, Cairo University, Kasr Al-Ainy, Cairo, Egypt. ${ }^{2}$ Washington University School of Medicine, St. Louis, USA. ${ }^{3}$ Cardiology Department, Faculty of Medicine, Cairo University, Kasr Al-Ainy, Cairo, Egypt.

Received: 5 May 2020 Accepted: 9 July 2020

Published online: 22 July 2020

\section{References}

1. Vander Hulst AE, Roest AW, Westenberg JM et al (2012) Cardiac MRI in postoperative congenital heart disease patients. JMRI 36(3):511-528

2. Rodríguez E, Soler R, Fernández R, Raposo I (2007) Postoperative imaging in cyanotic congenital heart diseases: Part1, Normal Findings. AJR 189:6

3. Masui T, Katayama M, Kobayashi S et al (2000) Gadolinium-enhanced MR angiography in the evaluation of congenital cardiovascular disease pre- and post-operative states in infants and children. J. Magn. Reson. Imaging 12: 1034-1042

4. Mercer-Rosa L, Yang W, Kutty S, Rychik J, Fogel M, Goldmuntz E (2012) Quantifying pulmonary regurgitation and right ventricular function in surgically repaired tetralogy of Fallot: a comparative analysis of echocardiography and magnetic resonance imaging. Circulation: Cardiovascular Imaging. 5(5):637-643 
5. Oosterhof T, Mulder BJ, Vliegen HW, de Roos A (2005) Corrected tetralogy of Fallot: delayed enhancement in right ventricular outflow tract. Radiology 237:868-871

6. Roest AA, Helbing WA (1999) vanderWall EE, deRoos A. Postoperative evaluation of congenital heart disease by magnetic resonance imaging. J. Magn.Reson. Imaging 10:656-666

7. Kreutzer C, DeVive J, Oppido G et al (2000) Twenty-five-year experience with Rastelli repair for transposition of the great arteries. J. Thorac. Cardiovasc. Surg. 120:211-223

8. Miura T, Kishimoto H, Kawata H, Hata M, Hoashi T, Nakajima T (2004) Management of univentricular heart with systemic ventricular out flow obstruction by pulmonary artery banding and Damus-Kaye-Stansel operation. Ann.Thorac.Surg. 77:23-28

9. Mavrouids C, Backer CL, Deal BJ (2003) Venous shunts and the Fontan circulation in adult congenital heart disease. In: Gatzoulis MA, Webb GD, Daubeney PEF (eds) Diagnosis and management of adult congenital heart disease. Churchill Livingstone, Edinburgh, Scotland, pp 79-83

10. Rodríguez E, Soler R, Fernández R, Raposo I (2007) Postoperative imaging in cyanotic congenital heart diseases: part 2, complications. AJR 189:6

11. Gewillig M (2005) The Fontan circulation. Heart 91:839-846

12. Steffens JC, Bourne MW, Sakuma H, O'Sullivan M, Higgins CB (1994) Quantification of collateral blood flow in coarctation of the aorta by velocity encoded cinemagnetic resonance imaging. Circulation 90:937-943

\section{Publisher's Note}

Springer Nature remains neutral with regard to jurisdictional claims in published maps and institutional affiliations.

\section{Submit your manuscript to a SpringerOpen ${ }^{\circ}$ journal and benefit from:}

- Convenient online submission

- Rigorous peer review

- Open access: articles freely available online

- High visibility within the field

- Retaining the copyright to your article

Submit your next manuscript at $\boldsymbol{\nabla}$ springeropen.com 